\title{
Hemşirelik Öğrencilerinin Bilgi ve İletişim Teknolojilerine Yönelik Tutumlarının Belirlenmesi
}

\author{
Eda ŞAHIN* \\ Tülay YAVAN ${ }^{\dagger}$ \\ Merve DEMIRHAN \\ Merve AYDIN $\$$ \\ İlknur YEŞİLÇINAR **
}

\begin{abstract}
$\ddot{O} \mathbf{z}$
Teknoloji ve bilimsel değişiklikler sağlık alanıyla da ilgilidir. Hemşirelik mesleğinin teknolojik ilerlemelerin gerisinde kalmaması, öğrenim esnasında teknolojileri kullanma becerilerini geliştirebilmeleri için hemşirelik öğrencilerinin bilgi ve iletişim teknolojileri konusunda tutumlarının belirlenmesi büyük önem taşımaktadır. Bu araştırma 358 hemşirelik lisans öğrencisi ile yapılmıştır. 'Tanıtıcı Bilgi Formu' ve 'Bilgi ve İletişim Teknolojilerine Yönelik Tutum Ölçeği' ile veriler toplanmıștır. Verilerin analizinde tanımlayıcı istatistik testleri, Kruskal Wallis ve Mann-Whitney U testleri kullanılmış, yanılma düzeyi p=0.05 olarak belirlenmiştir. Öğrencilerin bilgi ve iletişim teknolojilerine yönelik tutum ölçeği puan

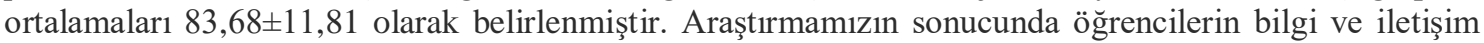
teknolojilerine yönelik tutumlarının olumlu yönde yüksek olduğu ve eğitim yılı, kişisel bilgisayara sahip olma, bilgisayar kullanma süresi arttıkça ölçek puanının da arttığ belirlenmiştir $(p<0.05)$.
\end{abstract}

Anahtar Kelimeler: Hemşirelik Öğrencileri, Bilgi ve İletişim Teknolojileri, Tutum

\section{Determination of Attitudes of Nursing Students towards Information and Communication Technologies}

\begin{abstract}
Technology and scientific changes are also related to the field of health. It is very important to determine the attitudes of nursing students about information and communication technologies so that the nursing profession does not lag behind technological advances and they can develop their skills to use technologies during education. Therefore, this research was planned and conducted with 358 nursing students studying in a nursing faculty. The data were collected with the 'Introductory Information Form' and 'Attitude Scale towards Information and Communication Technologies'. Descriptive statistics tests, Kruskal Wallis and Mann-Whitney U tests were used in the analysis of the data, and the error level was determined as $\mathrm{p}=0.05$. The average score of the students' attitude scale towards information and communication technologies was determined as $83.68 \pm 11.81$. As a result of our research, it was determined that students' attitudes towards information and communication technologies were positively high and the scale score increased as the year of education, owning a personal computer, and using computer increased ( $\mathrm{p}<0.05)$.
\end{abstract}

Keywords: Nursing students, Information and Communication Technologies, Attitude

Received/Geliş: 02.08.2019

Accepted/Kabul: 08.11.2019

Etik Kurul Başvuru tarihi:25.12.2015

Etik Kurul Rapor tarihi:05.01.2016

\footnotetext{
* Dr. Öğretim Üyesi, Giresun Üniversitesi Sağlık Bilimleri Fakültesi Hemşirelik Bölümü, edabasustaoglu@gmail.com, (D/0000-0001-9421-7689

† Prof., İzmir Ekonomi Üniversitesi Sağlık Bilimleri Fakültesi Hemşirelik Bölümü, tulay.yavan@ieu.edu.tr, (D/00000003-3287-1487

¥Araştırma Görevlisi, Giresun Üniversitesi Sağlık Bilimleri Fakültesi Hemşirelik Bölümü, mervedemirhan.7@gmail.com, (D/0000-0003-3543-9235

§Uzman Hemşire, Gülhane Eğitim ve Araştırma Hastanesi, mervemert1321@gmail.com, (D/0000-0002-7019-4096

** Dr. Öğretim Üyesi, İzmir Katip Çelebi Üniversitesi Sağlık Bilimleri Fakültesi Hemşirelik Bölümü, iyesilcinar14@gmail.com, D/0000-0003-2864-4935

(Makale türü: Araştırma makalesi)
} 


\section{Giriş}

Doksanlı yıllardan itibaren teknolojinin hızla büyümesi ile günlük hayatımızda bilgisayar ve buna bağlı teknolojinin kullanımı hızla yaygınlaşmıştır. Bu gelişmelere paralel olarak, "bilgi teknolojileri”, "bilgi ve iletişim teknolojileri” gibi terimler günümüzde sıkl1kla kullanılır olmuştur (Farzaneh, Ahmad, \& Mohd, 2014; Günbatar, 2014; Gündoğdu et al., 2018). Bilgi ve İletişim Teknolojileri (BİT), çeşitli yollarla bilgiyi oluşturmak, iletmek, depolamak, yorumlamak ve işlemek için kullanılan tüm bilgisayar ve iletişim araçlarını kapsayan, dünyada iletişime olanak sağlayan bir terimdir (Olutunu, Olalere, \& Solomon, 2015; Günbatar, 2014).

Sosyal hayatımızda da hızla yer alan BİT, eğitim alanını da etkisine alarak bilinen eğitim ve öğretim yöntemlerini değiştirmiştir (Çapık, 2018; Yen-Chun Jim Wu, 2017). Eğitim alanında BİT uygun şekilde kullanıldığında, bilgi birikimi ile verimli bir şekilde iş birliği yaparak ve çalışarak öğrencilerin becerilerini geliştirmek için temel bir araç olabilir (Farzaneh et al., 2014). BİT'in eğitim ve öğretim ile olan birlikteliği; öğrenci başarısının artmasında ve bilginin yapılandırılması süreçlerinde etkin bir rol oynamaktadır (Eryılmaz, 2018).

Teknoloji ve bilimsel değişiklikler sağlık alanıyla da ilgilidir (Terkes, Celik, \& Bektas, 2019). Bu alanda hemşirelik bilişsel, psikomotor ve davranışsal beceri gerektiren bir meslek olmasından dolayı hemşirelik eğitiminde yenilikçi uygulamaların kullanımı önemlidir. Hemşirelik mesleğinin amacı sağlık faaliyetlerinin geliştirilmesi, korunması ve hastalıkların önlenmesi olduğu göz önünde tutulduğunda bilimsel gelişmeleri uygulamada anahtar konumda yer almaktadır. Günümüz şartları gereği hemşirelik eğitiminin her aşamasında yeni öğrenme araç ve gereçlerin kullanımı artmıştır. Son yıllarda teknolojinin, eğitimcilerin hemşirelik öğrencilerini mevcut klinik ortamlar için hazırlamalarına olanak sağlayacağı, mevcut çalışan hemşireler için sağlık bakım hizmetini geliştireceği ve becerilerine katkıda bulunacağı belirtilmektedir (Korkmaz, 2018; Kaya, 2011; Kız1 \& Şendir, 2019).

Hemşirelik öğrencilerinin teknolojiye olan tutumunun incelendiği bir çalışmada teknolojiyi tıbbi ve mesleki amaçlı bilgiye ulaşmak için kullananların teknolojiye karşı daha olumlu bir tutuma sahip olduğu ifade edilmiştir (Terkes et al., 2019). Hemşirelik öğrencilerinde bakım hizmetleri sırasında klinik karar verme becerileri ile bilgisayar kullanımına yönelik tutumları arasındaki ilişkinin incelendiği bir çalışmada, bilgisayar kullanımı konusunda olumlu tutuma sahip olduğu belirlenen öğrencilerin klinik karar verme becerilerinin daha yüksek olduğu bulunmuştur (Özen, Yazıcıoğlu, \& Çınar, 2017). Tatlı ve arkadaşlarının, hemşirelerin ve öğrenci hemşirelerin bilgiye erişme amaçlı bilişim teknolojilerinden yararlanma düzeylerini belirlemek amacıyla yaptıkları çalışmada öğrenci hemşirelerin bilgi edinme, iletişim kurma ve kendilerini ifade etmek amaciyla bilişim teknolojilerini kullanma seviyelerinin hemşirelere göre daha yüksek olduğu bulunmuştur (Tatlı et al., 2018). Hemşirelik mesleğinin teknolojik ilerlemelerin gerisinde 
kalmaması, öğrenim esnasında teknolojileri kullanma becerilerini geliştirebilmeleri için hemşirelik öğrencilerinin bilgi ve iletişim teknolojileri konusunda tutumlarının belirlenmesi büyük önem taşımaktadır. Bu araştırma hemşirelik öğrencilerinin bilgi ve iletişim teknolojilerine yönelik tutumlarını belirlemek amacıyla yürütülmüştür.

\section{Gereç ve Yöntem \\ Evren ve Örneklem}

Gülhane Hemşirelik Yüksekokulunda 2015-2016 eğitim-öğretim yılında okuyan 375 öğrencinin 358'si araştırmanın örneklemini oluşturmuştur.

\section{Veri Toplama Araçları}

Veriler "Tanıtıcı Bilgi Formu", "Bilgi ve İletişim Teknolojilerine Yönelik Tutum Ölçeği”" kullanılarak elde edilmiştir.

Tanıtıcı Bilgi Formu; öğrencilerin sosyo-demografik özellikleri ve bilgisayar-internet kullanım olanaklarını içeren toplam 17 soru içermektedir.

Bilgi ve İletişim Teknolojilerine Yönelik Tutum Ölçeği (BİTTÖ); 2014'te Günbatar tarafından geliştirilen ölçek, beşli likert tiptedir. Ölçek, 23 maddeden ve beş alt boyuttan oluşmaktadır. Alt boyutlar sırasıyla; "Genel BİT Eğilimi”, "Sanal Ortamda Bilgiye Erişim", "Bilgisayar Donanımı", "Yazılım Kullanımı" ve "Sanal Ortamda İletişim”dir. Ölçekten en az 23 puan, en fazla 115 puan alınabilmektedir (Günbatar, 2014). Ölçeğin tamamından ve alt boyutlarından alınan puan arttıkça öğrencilerin bilgi ve iletişim teknolojilerine yönelik tutumları olumlu yönde değişmektedir. Bu çalışmada ölçeğin Cronbach alfa değeri 0.86 olarak bulunmuştur.

\section{Verilerin Toplanması}

Öğrencilere, araştırmaya katılımın gönüllülük esası olduğu ve araştırmanın amacı hakkında bilgi verilerek çalışmaya başlanmıştır. Her bir katılımcının veri toplama formunu doldurmas1 yaklaşık 20-30 dakika sürmüştür.

\section{Araştırmanın Etik Boyutu}

Araştırmanın yürütülebilmesi için etik kurul izni (2016126) alınmıştır.

\section{Verilerin Analizi}

Verilerin değerlendirilmesinde SPSS (Statistical Package for the Social Sciences) 15.0 For Windows kullanılmıştır ve frekans dağılımları ve tanımlayıcı istatistikler (ort \pm ss, medyan) verilmiştir. Verilerin normal dağ 11 ım gösterip göstermediği skewness ve kurtosis değerleri ile incelenmiştir. Araştırmada normal dağılım özelliği göstermeyen verilerin değerlendirilmesinde nonparametrik testlerden Kruskall Wallis, Mann Whitney U ve posthoc testleri kullanılmış, $\mathrm{p}<0.05$ değeri istatistiksel olarak anlamlı kabul edilmiştir. 
Eda ŞAHIN, Tülay YAVAN, Merve DEMIRHAN, Merve AYDIN, İlknur YEŞiLÇINAR

Hemşirelik Öğrencilerinin Bilgi ve İletişim Teknolojilerine Yönelik Tutumlarının Belirlenmesi

\section{Bulgular}

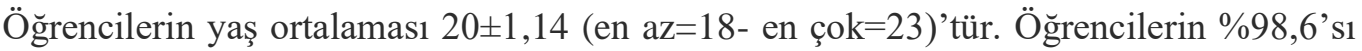
kadın ve \%83,5'i Anadolu Lisesinden mezundur. Öğrencilerin; \%92,2'si bilgisayardan yararlanmaya ihtiyaç duymaktadır, \%71,8'inin şahsına ait bilgisayarı bulunmaktadır, \%92,7'si aktif bir şekilde bilgisayar kullanmaktadır, \%62,3'ü orta derecede bilgisayar kullanma becerisine sahiptir, \%69,0’1 bilgisayar kullanmayı kendi kendine öğrenmiştir, \%68,2'si 5 yıl ve daha fazla süredir bilgisayar kullanmaktadır, \%5,.4’ü bilgisayar kullanmada eğitime ihtiyaç duymaktadır, \%91,3'ü bilgisayarı en çok internetten bilgi edinmek/ gündemi takip etmek/ araştırma yapmak amaçlı kullanmaktadır ve \%39,1'i bilgisayarı günde bir saatten daha kısa bir süre kullanmaktadır (Tablo 1).

Tablo 1. Öğrencilerin sosyodemografik ve bilgisayar-internet kullanım özellikleri

\begin{tabular}{|c|c|c|c|}
\hline & & $\begin{array}{l}\text { Kişi Sayısı } \\
(n=358)\end{array}$ & Yüzde (\%) \\
\hline Yaș Ortalaması & $20 \pm 1.14$ & & \\
\hline \multirow{2}{*}{ Cinsiyet } & Kadın & 353 & 98,6 \\
\hline & Erkek & 5 & 1,4 \\
\hline \multirow[t]{4}{*}{ Sinıfi } & Birinci sinıf & 114 & 31,8 \\
\hline & İkinci sınıf & 112 & 31,3 \\
\hline & Üçüncü sınıf & 75 & 20,9 \\
\hline & Dördüncü sınıf & 57 & 15,9 \\
\hline \multirow[t]{3}{*}{ Mezun olunan lise } & Düz lise & 49 & 13,7 \\
\hline & Fen lisesi & 3 & 0,8 \\
\hline & Anadolu lisesi & 299 & 83,5 \\
\hline \multirow[t]{2}{*}{ Kişisel bilgisayara sahip olma durumu } & Evet & 250 & 71.8 \\
\hline & Hayır & 101 & 28,2 \\
\hline \multirow[t]{2}{*}{ Bilgisayar kullanma durumu } & Evet & 332 & 92,7 \\
\hline & Hayır & 26 & 7,3 \\
\hline \multirow[t]{4}{*}{ Bilgisayar kullanma derecesi } & Kötü & 13 & 3,6 \\
\hline & Orta & 223 & 62,3 \\
\hline & İyi & 108 & 30,2 \\
\hline & Çok iyi & 14 & 3,9 \\
\hline \multirow{3}{*}{$\begin{array}{l}\text { Bilgisayar kullanmayı öğrenme kaynakları } \\
(*)\end{array}$} & & 195 & 54,5 \\
\hline & $\begin{array}{l}\text { Okul } \\
\text { Biloisavar kursu }\end{array}$ & 12 & 3,4 \\
\hline & $\begin{array}{l}\text { B1lgisayar Kursu } \\
\text { Kendi çabaları }\end{array}$ & 247 & 69,0 \\
\hline \multirow[t]{5}{*}{ Bilgisayar kullanma deneyimi } & 1 y1ldan az & & \\
\hline & $1-3$ y1l & 7 & 2,0 \\
\hline & $3-5$ y1l & 33 & 9,2 \\
\hline & 5 y1l ve üzeri & 74 & 20,7 \\
\hline & & 244 & 68,2 \\
\hline \multirow[t]{4}{*}{ Bilgisayar kullanma amacı (*) } & İnternet & 327 & 91,3 \\
\hline & Yazı yazma/Sunu hazırlama & 289 & 80,7 \\
\hline & $\begin{array}{l}\text { Eğlence amaçlı kullanım (Video } \\
\text { izleme /bilgisayar oyunu) }\end{array}$ & 259 & 72,3 \\
\hline & İletişim sağlama/haberleşme & 182 & 50,8 \\
\hline \multirow[t]{5}{*}{ Günlük bilgisayar kullanma saati } & 1 saatten az & & \\
\hline & $1-3$ saat & 140 & 39,1 \\
\hline & 3 - 5 saat & 106 & 29,6 \\
\hline & Gereksinim duydukça & 17 & 4,7 \\
\hline & & 95 & 26,5 \\
\hline
\end{tabular}

(*) Birden fazla seçenek işaretlenmiştir. 
Bilgisayar kullanımı konusunda öğrencilerin \%95,8'i bilgisayar kullanmanın hemşirelik eğitiminde iyi bir planlama, düzenleme ve karar vermeyi sağladığını, \%41,1'i bilgisayar kullanmanın fazla zamanlarını aldığını ve bilgisayarı sıklıkla amaç dışı kullandıklarını, \%93,0’1 bilgisayarın hemşirelik eğitiminde bilginin doğru, hızlı ve zamanında iletimini sağladığını, \%92,5'i hemşirelik eğitiminde bakım ve uygulamaların kolay öğrenilmesini sağladığını, \% 7,8'i sadece eğitim almış olan kişilerin bilgisayar kullanabildiğini ifade etmişlerdir (Tablo 2).

Tablo 2. Öğrencilerin bilgisayar kullanımı hakkında bazı görüşleri

\begin{tabular}{lll}
\hline & $\begin{array}{l}\text { Kişi Sayısı } \\
(\mathrm{n}=358)\end{array}$ & Yüzde (\%) \\
\hline $\begin{array}{l}\text { Hemşirelik eğitiminde bilgisayar kullanımı iyi bir } \\
\text { planlama, düzenleme ve karar vermeyi sağlar }\end{array}$ & & \\
$\begin{array}{l}\text { Evet } \\
\text { Hayır }\end{array}$ & 343 & 95,8 \\
\hline $\begin{array}{l}\text { Bilgisayar kullanımı öğrencilerin çok zamanlarını alır, } \\
\text { çoğ zaman amaç dışı kullanımlar gelişir }\end{array}$ & 15 & 4,2 \\
Evet & 147 & 41,1 \\
Hayır & 211 & 58,9 \\
\hline $\begin{array}{l}\text { Bilgisayar kullanımı hemşirelik eğitiminde bilginin } \\
\text { doğru, hızlı ve tam zamanında iletimine sebep olur }\end{array}$ & & \\
$\begin{array}{l}\text { Evet } \\
\text { Hayır }\end{array}$ & 333 & 93,0 \\
\hline $\begin{array}{l}\text { Bilgisayar kullanımı hemşirelik eğitiminde bakım ve } \\
\text { uygulamaların kolay öğrenilmesini sağlar }\end{array}$ & 25 & 7,0 \\
$\begin{array}{l}\text { Evet } \\
\text { Hayır }\end{array}$ & 331 & \\
\hline Yalnızca bilgisayar kullanımı konusunda eğitim görmüşş & 27 & 92,5 \\
olan kişiler bilgisayar kullanabilirler & & 7,5 \\
$\begin{array}{l}\text { Evet } \\
\text { Hayır }\end{array}$ & 28 & \\
\hline
\end{tabular}

\section{Öğrencilerin Bilgi ve İletişim Teknolojilerine Yönelik Tutumları}

Öğrencilerin BİTTÖ puan ortalamaları Tablo 3'de verilmiştir. Öğrencilerin BİTTÖ puan ortalamaları 83,68 $\pm 11,81$ (en az 29- en çok 115) olarak belirlenmiştir. Bilgi ve İletişsim

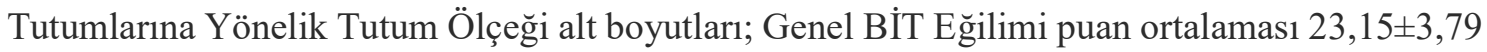
(min 6- max 30), Sanal Ortamda Bilgiye Erişim puan ortalamaları 20,66 $\pm 3,52$ ( $\min 5-\max 58$ ), Bilgisayar Donanımı puan ortalamas1 10,22 4,28 (min 4- max 20), Yazılım Kullanımı puan

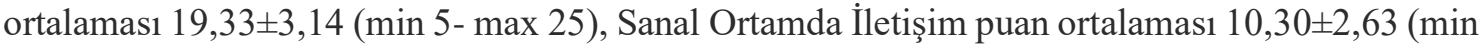
3- max 15) olarak bulunmuştur. 
Eda ŞAHIN, Tülay YAVAN, Merve DEMIRHAN, Merve AYDIN, İlknur YEŞiLÇıINAR

Hemşirelik Öğrencilerinin Bilgi ve İletişim Teknolojilerine Yönelik Tutumlarının Belirlenmesi

Tablo 3. Öğrencilerin BİTTÖ puan ortalamaları

\begin{tabular}{lccc}
\hline & $\mathbf{X} \pm \mathbf{S S}$ & En Az & En Çok \\
\hline Genel Bit Eğilimi & $23,15 \pm 3,79$ & 6 & 30 \\
Sanal Ortamda Bilgiye Erişim & $20,66 \pm 3,52$ & 5 & 58 \\
Bilgisayar Donanımı & $10,22 \pm 4,28$ & 4 & 20 \\
Yazılım Kullanımı & $19,33 \pm 3,14$ & 5 & 25 \\
Sanal Ortamda İletişim & $10,30 \pm 2,63$ & 3 & 15 \\
Toplam BİT & $83,68 \pm 11,81$ & 29 & 121 \\
\hline
\end{tabular}

Öğrencilerin BİTTÖ puan ortalamaları, sınıflar arasında istatistiksel olarak anlamlıdır $(\chi 2: 19,78 ; \mathrm{p}<0,001)$. Tabloda yer almayan verilerden posthoc testine göre üçüncü ve dördüncü sınıftaki öğrencilerin BİTTÖ puanlarının daha yüksek olduğu belirlenmiştir. Öğrencilerin kişisel bilgisayara sahip olma durumlarına göre BİT puan ortalamaları arasındaki fark istatistiksel olarak anlamlıdır (Z:-2,194; p<0,05). Kişisel bilgisayara sahip olan öğrencilerin BİT puan ortalamaları, kişisel bilgisayara sahip olmayan öğrencilerin BİTTÖ puan ortalamalarından anlamlı derecede daha yüksektir. Öğrencilerin bilgisayar kullanma sürelerine göre BİTTÖ puan ortalamaları arasındaki fark istatistiksel olarak anlamlıdır $(\chi 2: 10,03 ; \mathrm{p}<0,05)$. Öğrencilerin bilgisayar kullanma süreleri arttıkça BİTTÖ puan ortalamaları artmıştır. Öğrencilerin bilgisayar kullanma konusunda eğitime ihtiyaç duyma durumlarına göre BİTTÖ puan ortalamaları arasında istatistiksel olarak anlamlı fark vardır $(Z:-4,773 ; p<0,001)$. Bilgisayar kullanma konusunda eğitime ihtiyaç duyan öğrencilerin BİTTÖ puan ortalamaları anlamlı derecede daha yüksektir. Öğrencilerin bilgisayarı yazı yazma/sunum amacıyla kullanma durumlarına göre BİTTÖ puan ortalamaları arasında istatistiksel olarak anlamlı fark vardır $(Z:-2,578 ; p<0,05)$. Bilgisayarı yazı yazma/sunum amacıyla kullanan öğrencilerin BİTTÖ puan ortalamaları anlamlı derecede daha yüksektir. Öğrencilerin bilgisayarı iletişim amaçlı kullanma durumlarına göre BİTTÖ puan ortalamaları arasında istatistiksel olarak anlamlı fark vardır $(Z:-3,544 ; p<0,001)$. Bilgisayarı iletişim amaçlı kullanan öğrencilerin BİTTÖ puan ortalamaları anlamlı derecede daha yüksektir. Öğrencilerin bilgisayarı eğlence amaçlı kullanma durumlarına göre BİTTÖ puan ortalamaları arasında istatistiksel olarak anlamlı fark vardır (Z:-3,427; $\mathrm{p} \leq 0,001)$. Bilgisayarı eğlence amaçlı kullanan öğrencilerin BİTTÖ puan ortalamaları anlamlı derecede daha yüksektir (Tablo 4).

"Hemşirelik eğitiminde bilgisayar kullanımı iyi bir planlama, düzenleme ve karar vermeyi sağlar" ifadesine katılan öğrencilerin $(Z:-2,080 ; p<0,05)$ ve "Yalnızca bilgisayar kullanımı konusunda eğitim görmüş olan kişiler bilgisayar kullanabilirler" ifadesine katılan öğrencilerin BİTTÖ puan ortalamaları anlamlı derecede daha yüksektir $(Z:-2,008 ; p<0,05)$. "Bilgisayar kullanımı öğrencilerin çok zamanlarını alır, çoğu zaman amaç dışı kullanımlar gelişir” ifadesine katılan öğrencilerin BİTTÖ puan ortalamaları anlamlı derecede daha düşüktür (Z:-3,394; p<0,001) (Tablo 4). 
Tablo 4. Öğrencilerin aldıkları BİTTÖ puan ortalamalarının bazı özelliklere göre incelenmesi

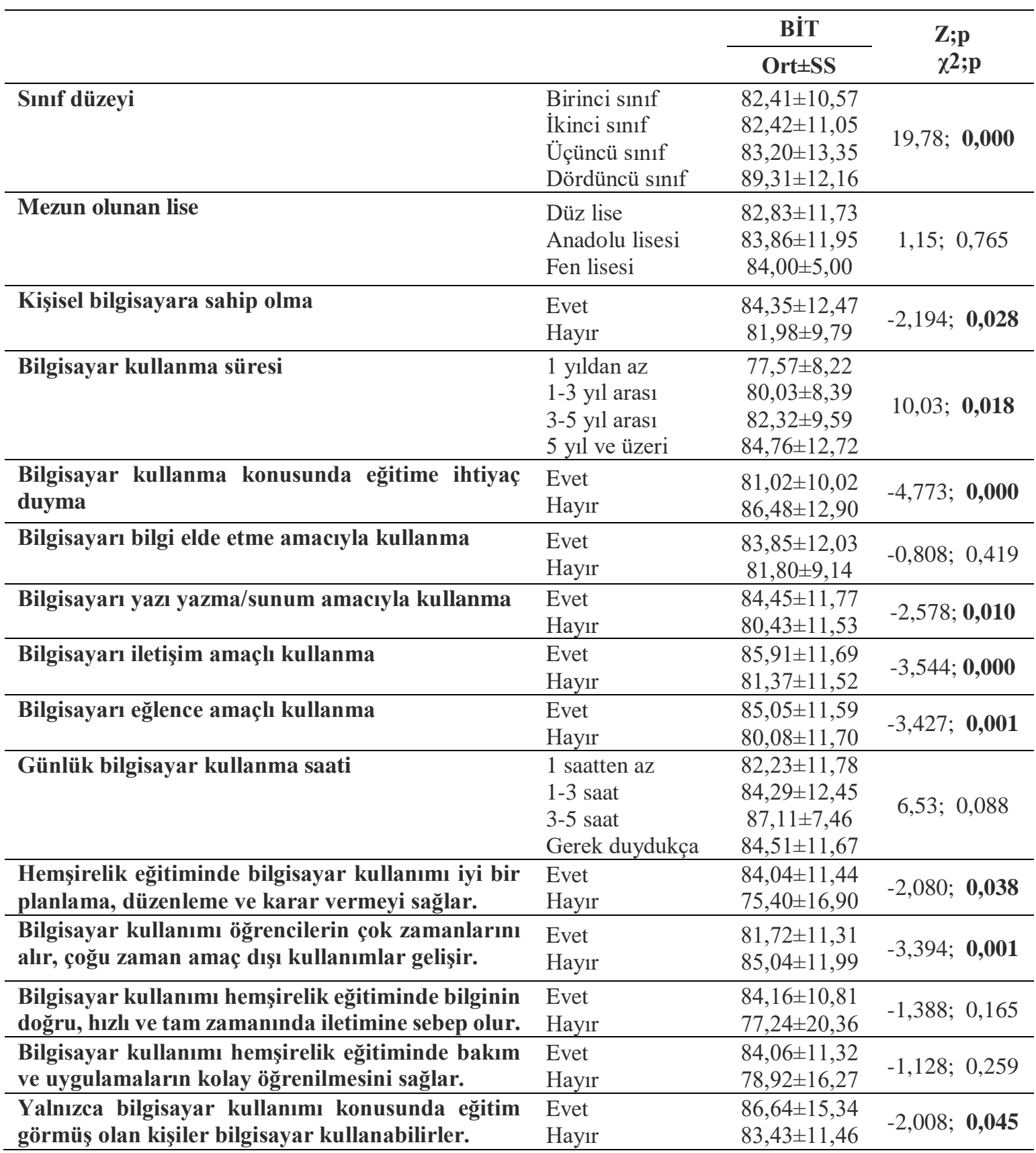

* $\chi 2$ :Kruskal Wallis testi $\quad * * Z$ Z:Mann Whitney U testi

\section{Tartışma}

$\mathrm{Bu}$ araştırma lisans öğrenimi gören hemşirelik bölümü öğrencilerinin bilgi ve iletişim teknolojilerine yönelik tutumlarını belirlemek amacı ile yapılmış olup öğrencilerin ölçek puan ortalamalarının olumlu olduğu belirlenmiştir. Araştırmamıza benzer şekilde aynı ölçeğin kullanıldığı başka bir çalışmada da tutumun olumlu olduğu saptanmıştır (Gündoğdu et al., 2018). Ebelik ve hemşirelik bölümü öğrencilerinin BİT’e yönelik tutumlarının incelendiği başka bir çalışmada ise tutumlarının daha olumsuz olduğu belirlenmiştir (Ayla Çapık, 2018). Aynı ölçeğin 
Eda ŞAHIN, Tülay YAVAN, Merve DEMIRHAN, Merve AYDIN, İlknur YEŞiLÇıINAR

Hemşirelik Öğrencilerinin Bilgi ve İletişim Teknolojilerine Yönelik Tutumlarının Belirlenmesi

kullanıldığ1 farklı branşlarda eğitim gören lisans öğrencilerinin BİT’e yönelik tutumlarının incelendiği bir çalışmada öğrencilerin tutumlarının orta düzeyde olduğu (Işıkgöz, 2015), diğer bir çalışmada ise öğrencilerin olumlu tutum içerisinde oldukları ifade edilmiştir (Güneş, Yüksel, \& Kaya, 2017). Öğretmen adaylarının BİT’e yönelik tutumlarının incelendiği diğer bir çalışmada ise tutumlarının orta düzeyde olduğu belirlenmiştir (Bakırcı \& Günbatar, 2017). Üniversite öğrencilerinin bilgi ve iletişim teknolojilerine yönelik tutumlarının bazı değişkenler açısından incelendiği bir çalışmada ise öğrencilerin olumlu tutum sergiledikleri belirtilmiştir (Ramazan Yirci, 2017). Yapılan çalışmalara bakıldığında günümüzde lisans eğitimi alan öğrencilerin teknolojiyi kullanmaya yönelik tutumlarının oldukça olumlu olduğu söylenebilir.

Araştırmamızda ölçeğin alt boyutları incelendiğinde en düşük puanın bilgisayar donanımı, en yüksek puanın genel BİT eğilimi alt boyutu olduğu belirlenmiştir. Literatür incelendiğinde araştırmamızın, Gündoğdu ve arkadaşlarının (2018), Yirci ve Aydoğar'ın (2017) çalışmaları ile paralellik gösterdiği saptanmıştır (Gündoğdu et al., 2018; Ramazan Yirci, 2017). Araştırmamızda öğrencilerin bilgisayarı kullanma amacı sorgulandığında en büyük oranın internet olduğu belirlenmiştir (Tablo 1). Buna göre öğrencilerin teknolojiyi daha çok tüketme eğilimi ile kullandıkları söylenebilir.

Araştırmamızda öğrencilerin sınıf düzeyi arttıkça BİTTÖ toplam puanlarının anlamlı derecede arttığ 1 tespit edilmiştir. Literatür incelendiğinde bu bulguyu destekleyen çalışmalar mevcuttur (Bakırcı \& Günbatar, 2017; Güneş et al., 2017). Sınıf düzeylerinin artması ile öğrencilerin ödev ve projelerde, çevresi ile iletişim kurmalarında teknolojiyi hayatlarına daha çok dâhil ettikleri söylenebilir.

Araştırmamızda kişisel bilgisayara sahip olan öğrencilerin BİTTÖ puan ortalamalarının kişisel bilgisayarı olmayan öğrencilere göre anlamlı düzeyde yüksek olduğu saptanmıştır. İlgili literatür değerlendirildiğinde lisans öğrencileri ile yapılan çalışmalarda bu bulguyu destekleyen çalışmalar mevcuttur (Gündoğdu et al., 2018; Güneş et al., 2017; Çapık, 2018). Kişisel bilgisayarın varlı̆̆ teknolojiye erişimi kolaylaştıran bir faktör olması nedeniyle olması beklenilen bir bulgu olarak değerlendirilmektedir. Özellikle hemşirelik öğrencileri için bilimsel bilgiye ulaşmada kişisel bilgisayarın varlığı önemli katkı sağlayabilir.

Araştırmamızda öğrencilerin bilgisayar kullanma süresi (yıl olarak) arttıkça BİTTÖ puan ortalamaları anlamlı derecede artmıştır. Günlük bilgisayar kullanımına bağlı olmaksızın bilgisayar kullanma deneyiminin artması bilgi ve iletişim teknolojilerine olan tutumu etkilemiştir. Bilgisayar kullanma eğitimine ihtiyaç duyan öğrencilerin puan ortalamalarının daha düşük olduğu göz önüne alınırsa öğrencilerin bilgisayar kullanımına ilişkin becerilere sahip olmaları önem arz etmektedir (Vijayalakshmi \& Math, 2013). Araştırmamızda 'hemşirelik eğitiminde bilgisayar kullanımı iyi bir planlama, düzenleme ve karar vermeyi sağlar' ve ‘yalnızca bilgisayar kullanımı 
konusunda eğitim görmüş olan kişiler bilgisayar kullanabilirler' ifadesine evet diyen öğrencilerin BİTTÖ puan ortalamaları anlamlı derecede daha yüksek bulunmuştur. Literatür incelendiğinde bilişim teknolojilerinin bir aracı olan bilgisayar kullanımı ile hasta bakımına katkı sağlanacağı ve hemşirelerin karar verme sürecinin geliştirileceği belirtilmektedir (Kardaş Özdemir \& Karakaya, 2017; Özen et al., 2017). Öğrencilerin lisans eğitimi sırasında aldıkları eğitimde BİT'den yararlanmaları, mezuniyet sonrası mesleki gelişimlerini sürdürmeleri ve güncel gelişmeleri takip edebilmeleri açısından oldukça önemlidir.

\section{Araştırmanın Kısıtlılıkları}

- Araştırmanın örneklemini sadece bir hemşirelik okulu öğrencileri oluşturmuştur. Bu araştırmadaki sonuçlar bütün hemşirelik öğrencilerine genellenemez.

- Oluşturulan veri toplama formlarına katılımcılar kendi bireysel ifadelerini yansıtmışlardır.

- Araştırmanın sonuçları uygulanan bilimsel veri formu ile sınırlıdır.

\section{Sonuç}

Araştırmamızın sonucunda öğrencilerin BİT'e yönelik tutumlarının olumlu yönde yüksek olduğu ve eğitim yıll, kişisel bilgisayara sahip olma, bilgisayar kullanma süresi arttıkça ölçek puanının da arttığı belirlenmiştir. Gelişen ve değişen teknolojik olanaklar sonucunda sağlık bakım hizmetlerinin sunumu sırasında bilgisayar teknolojilerinin kullanımının ve kontrolünün sağlanması kaçınılmaz hale gelmiştir. $\mathrm{Bu}$ nedenle hemşirelerin bilgisayar teknolojilerinin kullanımı konusundaki yeterliliklerinin yüksek düzeyde olması gerekmektedir. Bu çalışmadan ve literatürden elde edilen veriler doğrultusunda, bilgisayar teknolojilerinin sağlik bakım hizmetlerinde etkin bir şekilde kullanımının sağlanabilmesi için, hemşirelerin lisans eğitimi sırasında sağlık bakım hizmetlerinde bilgi ve iletişim teknolojilerinin kullanımı konusunda eğitim almaları gerekmektedir.

\section{Kaynakça}

Ayla Çapık, C. Ç., Yonca Kırba. (2018). Ebelik ve hemşirellik bölümü son sinif öğrencilerinin bilgi ve İletişim teknolojilerine yönelik tutumlarinin incelenmesi. Anadolu Hemşirelik ve Să̆llk Bilimleri Dergisi, 21(3), 163170.

Ayşe Çiçek Korkmaz, A. K. (2018). Hemşire Adaylarinin Hemşirelikte Bilgisayar Kullanimina Yöneli̇k Tutum Algilari. Sosyal Bilimler Dergisi $8(15)$.

Bakırc1, H., \& Günbatar, M. S. (2017). Öğretmen adaylarının bilgi okuryazarlık düzeyleri ile bilgi ve iletişim teknolojilerine yönelik tutumları. Ahi Evran Üniversitesi Kırşehir Eğitim Fakültesi Dergisi, 18(3), 543-563.

Eryılmaz, S. (2018). Öğrencilerin bilgi ve İletişim teknolojileri yeterliliklerinin belirlenmesi: Gazi üniversitesi, turizm fakültesi örneği Electronic Journal of Social Sciences, 17(65), 37-49. doi:10.17755/esosder.310987

Farzaneh, S., Rohani Ahmad, T., \& Ahmad Fauzi Mohd, A. (2014). Utilization of information and communication technologies in mathematics learning. Journal on Mathematics Education, 5(2),138-147. 
Eda ŞAHIN, Tülay YAVAN, Merve DEMIRHAN, Merve AYDIN, İlknur YEŞiLÇINAR

Hemşirelik Öğrencilerinin Bilgi ve İletişim Teknolojilerine Yönelik Tutumlarının Belirlenmesi

Florence Olutunu, D., Mudasiru Olalere, Y., \& Oloyede Solomon, O. (2015). Information and Communication Technology Literacy among Student-Teachers in Universities in Nigeria. Malaysian Online Journal of Educational Technology, 3(4), 13-22.

Günbatar, M. S. (2014). Bilgi ve İletişim Teknolojilerine Yönelik Bir Tutum Ölçeği Geliştirme Çalışması Ahi Evran Üniversitesi Kırşehir Eğitim Fakültesi Dergisi (KEFAD), 15(1), 121-135

Gündoğdu, H., Erol, F., Tanrıkulu, F., Filiz, N. Y., Kuzgun, H., \& Dikmen, Y. (2018). Hemşirelik öğrencilerinin bilgi ve iletişim teknolojilerine yönelik tutumlarının incelenmesi. Journal of Human Sciences, 15(1), 441-450.

Güneş, E., Yüksel, M., \& Kaya, P. (2017). Muhasebe eğitimi alan lisans öğrencilerinin bilgi ve iletişim teknolojilerine yönelik tutumları. Ahi Evran Üniversitesi Kırşehir Eğitim Fakültesi Dergisi, 18(1), 367-382.

Handenur Gündoğdu, Funda Erol, Fatma Tanrıkulu, Nasibe Yağmur Filiz, Hürmüs Kuzgun, \& Dikmen, Y. (2018 ). Hemşirelik öğrencilerinin bilgi ve iletişim teknolojilerine yönelik tutumlarının incelenmesi. International Journal of Human Sciences, 15 (1 ), 441-450. doi:10.14687/jhs.v15i1.5052

Işıkgöz, E. (2015). Beden Eğitimi Ve Spor Öğretmenliği Bölümü Öğretmen Adaylarının Bilgi Ve İletişim Teknolojilerine Yönelik Tutumlar1: Batman Üniversitesi Örneği Journal of Life Sciences, 5(2).

Kardaş Özdemir, F., \& Karakaya, G. (2017). Hemşirelerin bilgisayar ve bilişim teknolojisini kullanma durumları. İzmir Tepecik Ĕ̌itim ve Araştırma Hastanesi Dergisi, 27(2), 126-130.

KAYA, N. (2011). Factors Affecting Nurses' Attitudes Toward Computers in Healthcare. CIN: Computers, Informatics, Nursing, 29(2), 121-129. doi:10.1097/NCN.0b013e3181f9dd0f

Kızıl, H., \& Şendir, M. ( 2019). Innovative approaches in nursing education. International Journal of Human Sciences, $16(1)$.

Özen, N., Yazıcıŏlu, İ., \& Çınar, F. İ. (2017). Hemşirelik öğrencilerinin sağlık bakımında bilgisayar kullanımına yönelik tutumları ile klinik karar verme becerileri arasındaki ilişkinin incelenmesi.

Ramazan Yirci, N. A. (2017). Üniversite öğrencilerinin bilgi ve iletişim teknolojilerine yönelik tutumlarinin bazi değişkenler açisindan incelenmesi. ulakbilge, 5(18). doi:10.7816/ulakbilge-05-18-13

Tatlı, Z., Aydın, A., Şimşek, P., Özdemir, M., Gölbaşı, S., Karacan, S., . . Gündüz, A. (2018). Hemşirelerin ve Hemşirelik Öğrencilerinin Bilişim Teknolojilerini Kullanma Durumları. Ordu Üniversitesi Hemşirelik Çalışmaları Dergisi, 1(1), 18-27.

Terkes, N., Celik, F., \& Bektas, H. (2019). Determination of nursing students' attitudes towards the use of technology. Japan Journal of Nursing Science, 16(1), 17-24.

Vijayalakshmi, P., \& Math, S. B. (2013). Response and attitudes of undergraduate nursing students towards computers in health care. Canadian Journal of Nursing Informatics Online, 8(3).

Yen-Chun Jim Wu, C.-I. P. C.-H. Y. (2017). Attitudes towards the use of information and communication technology in management education. Behaviour \& Information Technology 36,(3), 243-254 doi:10.1080/0144929X.2016.1212928 